OPEN ACCESS

Edited by: Robert Zeiser,

University of Freiburg, Germany

Reviewed by:

Cynthia Giver,

Emory University, United States

Meng LV,

Peking University People's Hospital,

China

*Correspondence:

John E. J. Rasko

j.rasko@centenary.org.au

Specialty section:

This article was submitted to Alloimmunity and Transplantation,

a section of the journal

Frontiers in Immunology

Received: 20 August 2021

Accepted: 07 October 2021

Published: 26 October 2021

Citation:

Kelly K and Rasko JEJ (2021)

Mesenchymal Stromal Cells

for the Treatment of Graft

Versus Host Disease.

Front. Immunol. 12:761616.

doi: 10.3389/fimmu.2021.761616

\section{Mesenchymal Stromal Cells for the Treatment of Graft Versus Host Disease}

\author{
Kilian Kelly ${ }^{1}$ and John E. J. Rasko ${ }^{2,3,4 *}$ \\ ${ }_{1}^{1}$ Cynata Therapeutics Limited, Cremorne, VIC, Australia, ${ }^{2}$ Department of Cell and Molecular Therapies, Royal Prince Alfred \\ Hospital, Sydney, NSW, Australia, ${ }^{3}$ Gene and Stem Cell Therapy Program Centenary Institute, University of Sydney, Sydney, \\ NSW, Australia, ${ }^{4}$ Central Clinical School, Faculty of Medicine \& Health, University of Sydney, Sydney, NSW, Australia
}

Graft versus host disease (GvHD) is a life-threating complication of allogeneic hematopoietic stem cell transplantation, which is initially treated with high dose corticosteroids. Approximately 50\% of acute GvHD cases are resistant to steroid treatment, and two-year mortality rates in those steroid-resistant patients exceed 80\%. Chronic GVHD necessitates prolonged corticosteroid use, which is typically associated with limited efficacy and troublesome adverse effects. No agent has yet been established as an optimal second line therapy for either acute or chronic GvHD, but mesenchymal stromal cells (MSCs) have shown substantial promise. MSCs promote an immunosuppressive and immunoregulatory environment via multifactorial mechanisms, including: secretion of proteins/peptides/ hormones; transfer of mitochondria; and transfer of exosomes or microvesicles containing RNA and other molecules. A large number of clinical studies have investigated MSCs from various sources as a treatment for acute and/or chronic GvHD. MSCs are generally safe and well tolerated, and most clinical studies have generated encouraging efficacy results, but response rates have varied. Confounding factors include variability in MSC donor types, production methodology and dose regimens, as well as variations in study design. It is wellestablished that extensive culture expansion of primary donor-derived MSCs leads to marked changes in functionality, and that there is a high level of inter-donor variability in MSC properties. However, recent manufacturing innovations may be capable of overcoming these problems. Further adequately powered prospective studies are required to confirm efficacy and establish the place of MSC therapy in the treatment of this condition.

Keywords: graft versus host disease (GvHD), mesenchymal stromal (stem) cell (MSC), stem cell, bone marrow transplant (BMT), allogeneic

\section{INTRODUCTION}

Allogeneic hematopoietic stem cell transplantation (HSCT) offers a potentially curative option for conditions including hematological malignancies. However, its benefits are often limited by serious complications, including graft versus host disease (GvHD).

GvHD arises from donor T-lymphocytes attacking host tissues. Features of GvHD may be categorized as either acute or chronic, which were historically distinguished by the time of occurrence $(<100$ or $>100$ days post-transplant) (1). However, this is likely an over- 
simplification, because acute GvHD may persist beyond 100 days, and there may be overlap between acute and chronic syndromes (2). Both acute and chronic GvHD commonly affect the skin. Chronic GvHD is characterized by an initial lichenoid stage, similar to acute skin GvHD (3), often followed by a distinct sclerotic stage (4). Other organs typically affected by acute GvHD are the liver and gastrointestinal tract. Chronic GvHD may affect almost any organ in the body (5).

GvHD is the cause of death in $8-16 \%$ of adult allogeneic HSCT recipients (6). It should be noted that these figures likely underestimate the extent to which GvHD contributes to posttransplant mortality, given that GvHD may also predispose HSCT recipients to other common causes of death, such as organ failure, infection and hemorrhage.

Acute GvHD is typically staged and graded according to criteria established at the 1994 Consensus Conference on Acute GvHD Grading (7). In most clinical trials, response to treatment is measured based on improvement in the severity of GvHD by at least one grade (Partial Response; PR) and/or resolution of all acute GvHD signs or symptoms, i.e. a return to Grade 0 (Complete Response; CR). The term Overall Response (OR) rate refers to the sum of $\mathrm{PR}$ and $\mathrm{CR}$ rates. Similarly, consensus criteria have also been developed for chronic GvHD, under which a global severity score is based on two different scores of the severity of cutaneous disease (8).

The prophylaxis and management of GvHD is complex, and approaches vary substantially between centers worldwide (9). Corticosteroids remain the mainstay of first-line treatment for both acute and chronic GvHD. Approximately 50\% of acute GvHD cases prove to be resistant to high doses of steroids, and the prognosis in those patients is extremely poor, with two-year overall survival (OS) rates below 20\% (10). In moderate-severe chronic GvHD, systemic steroid treatment for at least one year is typically required, with approximately $50-60 \%$ of patients requiring secondary "steroid-sparing" treatment (such as antithymocyte globulin (ATG), extracorporeal photopheresis (ECP) or mycophenolate mofetil), and more than $10 \%$ requiring systemic treatment for over seven years (11). Even when steroid treatment is effective in chronic GvHD patients, it may be associated with severe adverse effects, especially when administered systemically for lengthy periods.

Diverse second-line agents have been investigated for the treatment of GvHD after the failure of steroids. In 2019, the Janus kinase inhibitor ruxolitinib (Jakaf ${ }^{\circledR}$, Incyte Corporation) was approved in the USA for the treatment of steroid resistant acute GvHD (SR-aGvHD) (12). In July 2021, the rho kinase (ROCK) inhibitor belumosudil (Rezurock ${ }^{\mathrm{TM}}$, Kadmon Pharmaceuticals) was approved in the USA, for the treatment of chronic GvHD after failure of at least two prior lines of systemic therapy (13). Both of these recent approvals apply to adults and children over 12 years of age only. Other agents investigated for acute GvHD include ATG, anti-CD26 antibodies, and $\operatorname{ECP}(14,15)$. An even wider range of agents has been investigated for chronic GvHD, including Janus kinase inhibitors, tyrosine kinase inhibitors, proteasome inhibitors, monoclonal antibodies, and fusion proteins (16). However, to date no agent has been established as an optimal second line therapy for either acute or chronic GvHD, and there remains a need for new therapies with superior safety and efficacy profiles.

The subject of this review is the use of mesenchymal stromal cells (MSCs) in the context of GvHD. Over the past two decades, there has been extensive interest in the potential therapeutic use of MSCs in a wide range of clinical settings (17), including in support of HSCT (18) and in the treatment of GvHD (19).

\section{MECHANISM OF ACTION}

MSCs lack human leucocyte antigen (HLA) Class II expression, which allows allogeneic administration without donor-recipient matching. MSCs exert multifactorial effects, including: paracrine activity involving secretion of proteins/peptides and hormones; transfer of mitochondria by way of tunneling nanotubes or microvesicles; and transfer of exosomes or microvesicles containing RNA and other molecules (Figure 1) (20, 21).

MSCs promote an immunosuppressive and immunoregulatory environment, by secretion of cytokines, chemokines, growth factors and extracellular vesicles $(22,23)$. Notably, MSCs constitutively secrete indoleamine 2,3-dioxygenase (IDO), and activation of MSCs by inflammatory cytokines including interferon-gamma (IFN- $\gamma$ ) and tumor necrosis factor-alpha (TNF- $\alpha$ ) leads to upregulation of this IDO secretion $(24,25)$. IDO, in turn, leads to suppression of allogeneic T cell proliferation (26). Further immunomodulatory effects of MSCs are mediated via effects on B cells, natural killer cells, monocytes and dendritic cells (24). An interesting idea is that apoptosis of MSCs in vivo contributes to their immunomodulatory effects, a phenomenon that may be mediated through the production and release of apoptotic extracellular vesicles (27). Additionally, when undergoing apoptosis, MSCs induce IDO production in recipient phagocytes (28). It has also been shown that amelioration of GvHD in a humanized mouse model was associated with altered phosphorylation and cellular localization of the $\mathrm{T}$ cell-specific kinase, Protein Kinase C theta (PKCO) (29).

Aside from immunomodulation, MSCs have also been shown to limit tissue damage and stimulate tissue repair, primarily as a result of paracrine effects on other endogenous recipient cells (20).

\section{CLINICAL EXPERIENCE}

The use of MSCs to treat GvHD in a human subject was first reported in 2004 by Le Blanc et al, of Karolinska Institutet, Sweden (30). After receiving an allogeneic HSCT from a HLAmatched, unrelated donor, a nine-year-old boy developed Grade IV acute GvHD, which was refractory to treatment with corticosteroids and several second-line agents. The authors reported that the other 24 patients at their center who had experienced such severe acute GvHD had all died within 6 months, with a median survival of just 2 months. In this case, the patient was treated with two intravenous (IV) infusions 


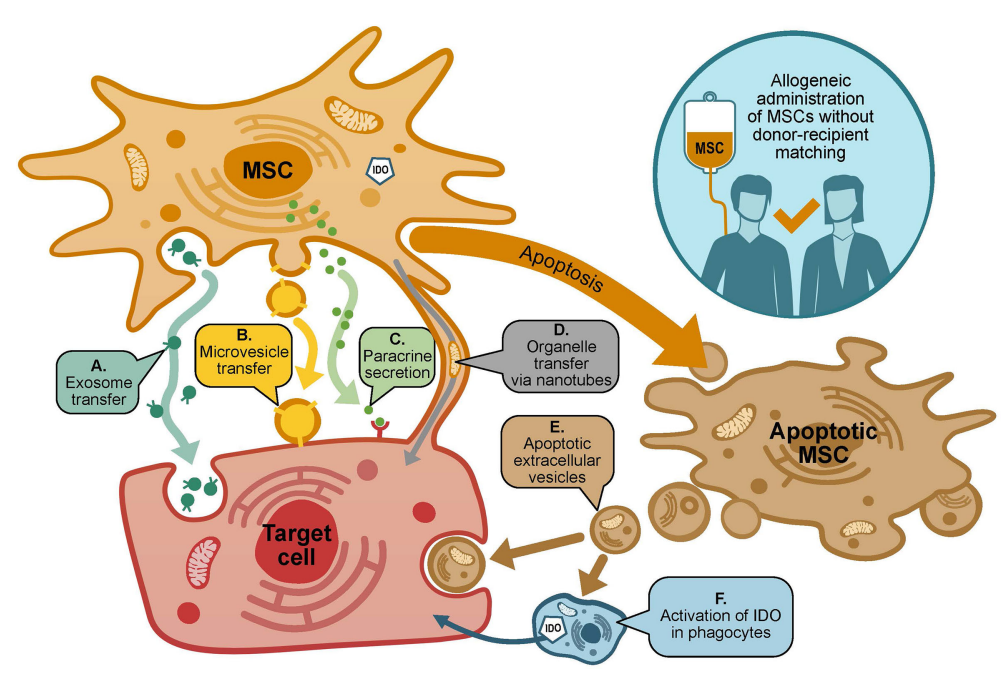

FIGURE 1 | Mechanisms of action of MSCs in GVHD. MSCs may exert many effects on target cells via diverse potentially-overlapping mechanisms. Target cells include (i) donor and host immune cells, including T cells, B cells, NK cells, monocytes and dendritic cells; and (ii) host cells susceptible to damage by GvHD, e.g. cells of the skin, gastrointestinal tract and liver. Potential mechanisms through which MSCs may act include (A, B): transfer of exosomes or microvesicles containing RNA and other molecules; (C) paracrine activity including secretion of proteins (including IDO), peptides and hormones; (D) transfer of organelles via tunneling nanotubes; (E, F) MSC apoptosis results in the release of apoptotic extracellular vesicles that act on target cells, as well as induction of IDO production in recipient phagocytes.

of bone-marrow-derived allogeneic MSCs (on Days 73 and 150 post HSCT) from a related donor (his mother). The first infusion was followed by a marked but incomplete improvement, while after the second infusion the patient appeared to have recovered completely, and he remained alive and well after one year.

Since that initial case report, numerous clinical trials have been conducted to investigate MSCs as a treatment for GvHD. As of 30 June 2021, a total of 43 interventional clinical trials/ expanded access programs involving MSCs as a treatment for GvHD have been registered on clinicaltrials.gov. Of those studies, 19 are complete, and papers summarizing the results of 10 have been published. Papers summarizing a further 17 studies involving patients with GvHD that were not registered on clinicaltrials.gov have also been published (studies conducted outside of the USA are not required to be registered on clinicaltrials.gov). Table 1 summarizes the overall characteristics of the published and unpublished studies registered on clinicaltrials.gov.

The vast majority of studies have involved allogeneic MSCs, with bone marrow being the most common tissue source. A small number of trials have used MSCs derived from cord blood or adipose tissue, and a single study to date has been undertaken using iPSC-derived MSCs. The trials have been conducted by a wide range of sponsors, including both academic and commercial institutions.

As summarized in Table 2, most $(\mathrm{n}=18)$ published studies included only patients with SR-aGvHD. The patient population varied across other studies: five included patients with either SRaGvHD or chronic GvHD; two included only patients with chronic GvHD; one included patients with either SR-aGvHD or newly diagnosed acute GvHD; and one included only patients with newly diagnosed acute GvHD.

TABLE 1 | Overall Summary of Characteristics of Clinical Studies of MSCs in GVHD $(n=60)$.

\begin{tabular}{|c|c|c|c|c|c|}
\hline Study Type & $\mathbf{n}$ & Age group & $\mathrm{n}$ & MSC Source & $\mathbf{n}$ \\
\hline Phase 1 & 12 & Adults only & 23 & Bone marrow & 42 \\
\hline Phase $1 / 2$ & 15 & Adults and children & 32 & Cord blood & 7 \\
\hline Phase 2/3 & 4 & & & iPSCs & 1 \\
\hline Phase 3 & 6 & Registered on clinicaltrials.gov & 43 & Not stated & 8 \\
\hline Compassionate use & 10 & Not yet recruiting & 3 & & \\
\hline Acute GvHD & 40 & Withdrawn/terminated & 2 & Autologous & 57 \\
\hline Acute or chronic GvHD & 10 & Complete & 19 & Not stated & 2 \\
\hline Chronic GvHD & 10 & Unknown & 13 & & \\
\hline
\end{tabular}


TABLE 2 | Summary of Published Clinical Studies of MSCs in GrHD.

First-line Treatment of Acute GvHD, in Combination With Corticosteroids

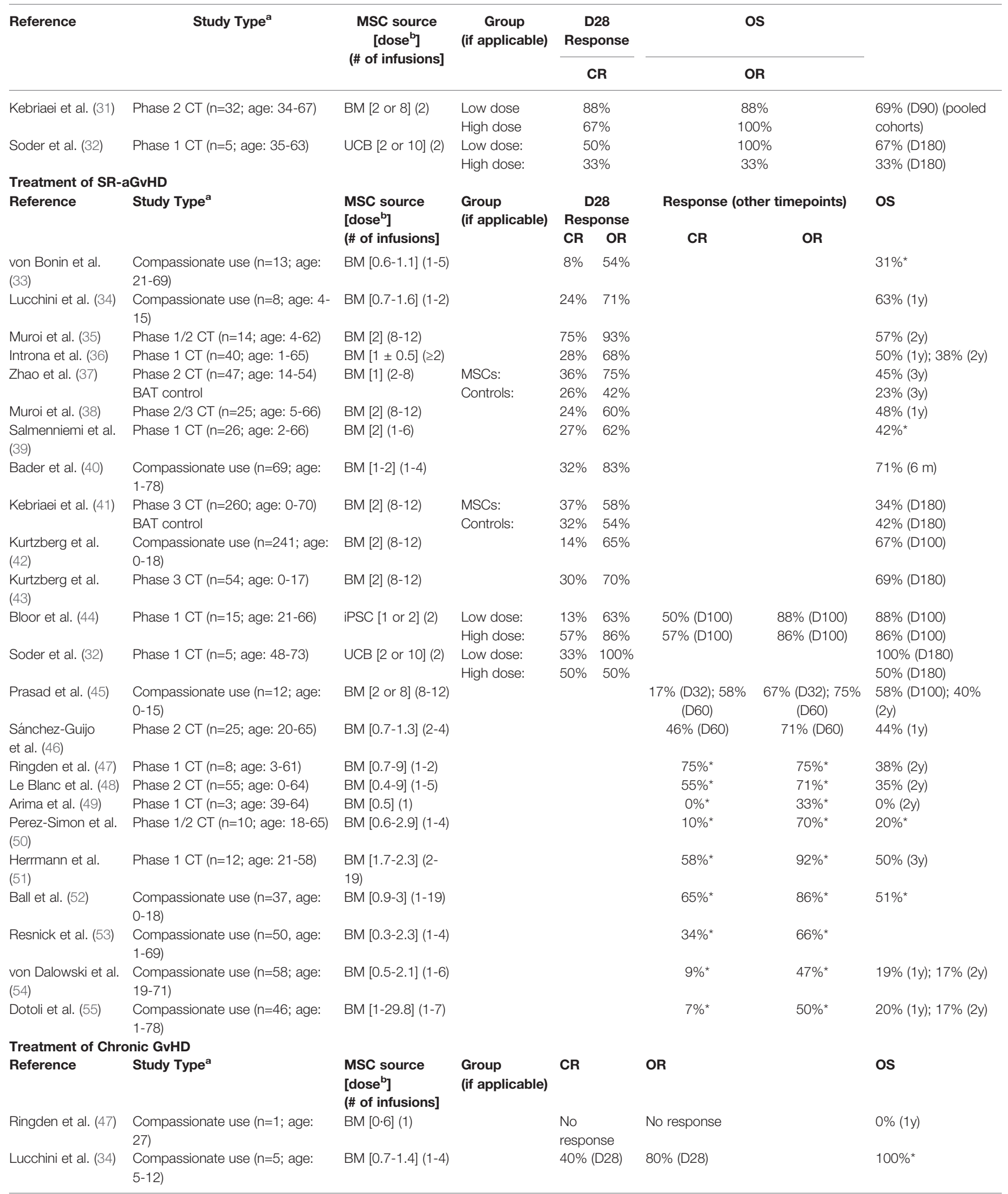


TABLE 2 | Continued

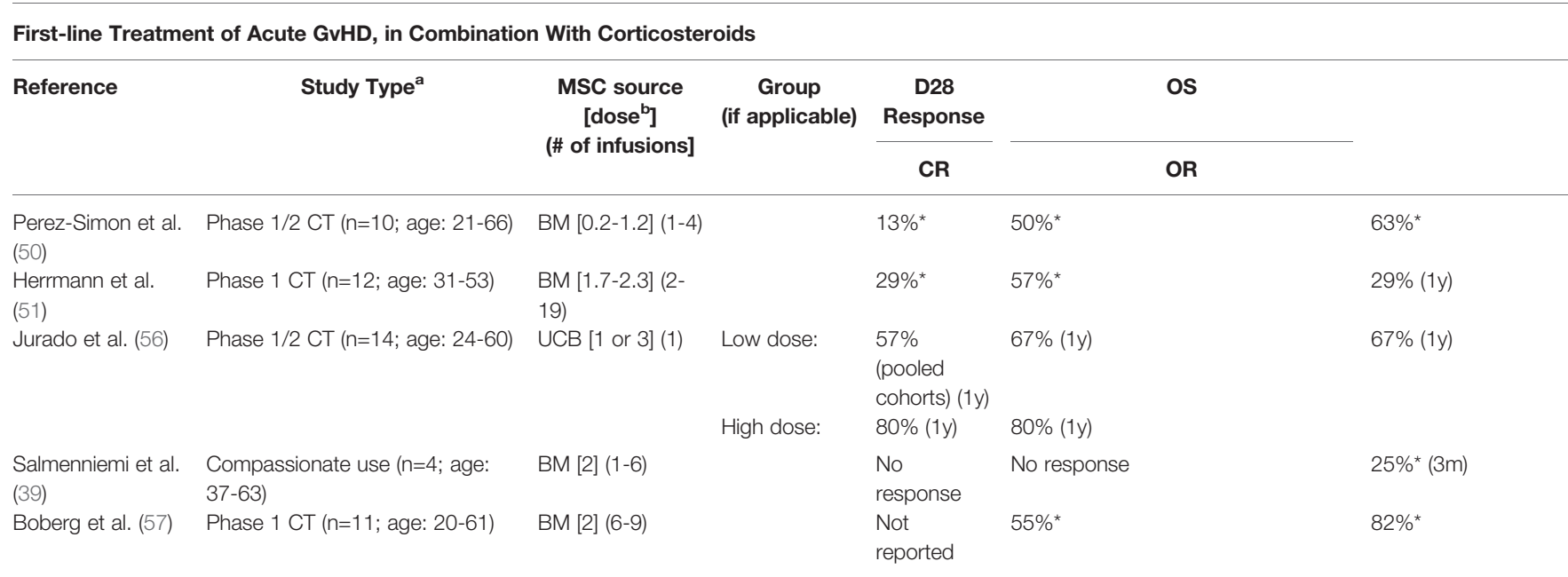

a. No internal control group unless stated.

b. Dose expressed as $10^{6} \mathrm{cell} / \mathrm{kg}$.

CR, complete response; OR, overall response; OS, overall survival; CT, clinical trial; BAT, best available therapy; BM, bone marrow; AT, adipose tissue; UCB, umbilical cord blood; iPSC, induced pluripotent stem cell; $y$, year; $D$, day.

* Timeframe for assessment not specified, and duration of follow-up varied between patients in some cases.

\section{DISCUSSION}

There is broad consensus that MSCs are generally safe and well tolerated $(17,21)$. None of the published studies of MSCs in GvHD reviewed here identified any significant safety issues. This is consistent with the wider experience of MSCs in the treatment of other conditions. A systematic review of MSCs in 55 clinical trials, in which 2,696 patients received MSC treatment, found an association between MSCs and transient fever, but not with acute infusional toxicity, infection, thrombotic/embolic events, death or malignancy (58).

Clinical studies of MSCs for SR-aGvHD in particular have generated encouraging efficacy results, but response rates have varied. For example, four studies of MSCs in SR-aGvHD have reported D28 OR rates exceeding $80 \%(32,35,40,44)$ and a further three have reported D28 OR rates of at least $70 \%(34,37,43)$. However, a number of other published studies have reported lower D28 OR rates, ranging from $50-68 \%(33,36,38,39,41,42)$.

There has been even greater variability in D28 CR rates, with an overall range of $8-75 \%$ reported in SR-aGvHD patients (3244). Notably, CR and OR rates do not necessarily correlate: one study that reported a very high D28 OR rate (93\%) also reported a very high $\mathrm{D} 28 \mathrm{CR}$ rate (75\%), while another study reported a D28 OR rate of $100 \%$, but a CR rate of just $33 \%(32,35)$. While the latter study had a very small sample size $(n=5)$, this inconsistency was also evident in larger studies: in a compassionate use study with the commercial MSC product remestemcel-L $(n=241)$ the D28 OR and CR rates were $65 \%$ and $14 \%$ (i.e. $21 \%$ of responders were complete responders) (42); while in a Phase 3 clinical trial with the same product $(n=260)$, the D28 OR and CR rates were $58 \%$ and $37 \%$ (i.e. $64 \%$ of responders were complete responders).

Overall, outcomes with MSCs compare favorably to those reported with other second-line agents. In clinical trials in patients with SR-aGvHD, ruxolitinib treatment led to D28 OR rates of $55-62 \%$ and D28 CR rates of $27-34 \%(59,60)$; etanercept treatment led to D28 OR rates of $50-53 \%$ and D28 CR rates of 0 $20 \%(61,62)$; while one-month OR and CR rates in patients treated with ECP were $<50 \%$ and $33 \%$, respectively (63). It should also be noted that some safety concerns have been associated with ruxolitinib and etanercept.

Caution must be exercised in comparing results between studies. Confounding factors include variability in MSC donor types, MSC dose per infusion, and number of infusions per patient - even within the same trial in some instances. A further issue is that there is no universally accepted definition of steroidresistance. Clinical trials in SR-aGvHD typically require patients to have failed to respond despite treatment with corticosteroids, but the minimum period of treatment required varies between trials [e.g. 3 days (48) or 7 days (41)]. Additionally, many of the published studies have been compassionate use programs rather than formal, prospective clinical trials, while most of the clinical trials have been open-label studies with no control group.

Importantly, there has also been a lack of standardization on the timeframe for assessment of outcome measures. The most common timepoint to assess acute GvHD response has been 28 days, and for that reason D28 CR and OR rates are shown in separate columns in Table 2. However, some studies assessed CR and OR at different specified timepoints, while in many studies the timeframe for response assessment was not specified, meaning that a response at any time during follow-up was counted. In studies where response rates were assessed at more than one timepoint, there was a marked increase in response rates at later timepoints $(44,45)$. Consequently, D28 response rates cannot be compared with response rates at later timepoints, or response rates at unspecified timepoints.

Similarly, many studies have reported OS rates at the time of last follow-up, and the duration of follow-up per patient has 
typically varied both within and between studies. Furthermore, some studies have reported OS only at early timepoints such as D100 or D180, which are likely to be too soon to draw any conclusions.

Greater standardization in the design of future clinical trials would facilitate more robust evaluation of the efficacy of potential GvHD treatments. In recent years, D28 OR rate has been the primary endpoint in several Phase 2 and 3 clinical trials in SR-aGvHD, including those that supported FDA approval of ruxolitinib $(43,59,60)$. Although not necessarily the primary endpoint, this outcome measure has also been reported in numerous other MSC trials, along with D28 CR rate (32-42, 44). Another important consideration is what, if any, control group to include. Until recently, as there were no treatments specifically approved for SR-aGvHD, the only ethical control options in SR-aGvHD trials were: a best available therapy (BAT) control group; an external control group; or no control group. Each of those options had limitations, but in light of the recent FDA approval, the possibility now exists to conduct trials in SRaGvHD with ruxolitinib as a control. A proposed Phase 3 trial of a monoclonal antibody-based treatment in SR-aGvHD was recently registered on clinicaltrials.gov, which aims to demonstrate that the investigational agent is superior to ruxolitinib based on D28 CR rate (64). A similar design may be suitable for late-stage trials of MSC products, while a noninferiority design might also be sufficient to support approval, especially as MSCs appear to have a very good safety profile. However, the inclusion of a ruxolitinib control might remain challenging in multinational studies, as ruxolitinib is not yet approved for the treatment of SR-aGvHD in the European Union or many other jurisdictions.

Another notable variable lies in the MSC manufacturing processes used. Academic studies have typically used minimally expanded bone marrow-derived MSCs, but most commercially-sponsored studies have utilized bone marrowderived MSCs that were extensively expanded using industrialscale processes.

The initial trial with a commercially produced bone marrowderived product (remestemcel-L) in acute GvHD showed positive results (31). However, the results of that study are difficult to interpret in the context of other published studies, as it involved first-line treatment of acute GvHD in combination with corticosteroids, rather than treatment of SR-aGvHD. Additionally, the study did not include a control group, and first-line acute GvHD treatment with corticosteroids in the absence of MSCs has been shown to result in CR and OR rates as high as $69 \%$ and $78 \%$, respectively (65). A subsequent randomized-controlled Phase 3 trial of remestemcel-L in patients with SR-aGvHD was completed in 2009, but with disappointing outcomes, which were belatedly published in 2020 (41). The trial found that remestemcel-L treatment led to significantly improved OR and durable CR rates in patients with liver GvHD. There was also a higher OR rate in children treated with remestemcel-L compared to controls. Nonetheless, the trial failed to meet its primary endpoint - there was no statistical difference between the durable complete response rate in patients treated with remestemcel-L in comparison to those treated with placebo. In more recent years, further trials with remestemcel-L in SR-aGvHD have been completed, including: two single arm, open-label clinical trials in adults and children in Japan $(n=14$ and $n=25$, respectively) $(35,38)$; a single arm, open-label clinical trial in children in the USA $(n=51)$ (43) and a large compassionate use study in children in the USA $(n=241)(42)$. Those studies have generated more positive results, but CR rates in particular have been mixed (24-75\% in Japan, and $14-30 \%$ in the USA).

A number of suggestions have been offered to explain the apparent inconsistency in outcomes between trials. A review published in 2013 observed that the most striking difference between academic and commercial MSC treatments was the extent of MSC expansion - ranging from the production of 5-10 doses per bone marrow donation at academic centers, to 10,000 doses with remestemcel-L (66). There is a substantial body of evidence in the literature demonstrating that extensive culture expansion of bone marrow-derived MSCs leads to marked changes in functionality $(67,68)$. There is also evidence that clinical efficacy of MSCs is impaired even by modest levels of expansion (69).

It is well-established that there is a high level of inter-donor variability in MSC properties. For example, MSC gene expression, differentiation, proliferation and colony-forming capacity vary markedly between donors $(67,70)$. The susceptibility of MSCs to activation by IFN- $\gamma$ and TNF- $\alpha$, and the consequent upregulation of IDO expression and suppression of T cell proliferation, is also donor-dependent $(24,71,72)$. With respect to processes that rely on isolation of MSCs from random donors, this variability may lead to an unpredictable variability in efficacy - between, and potentially within, studies.

It has also been suggested that cryopreserving MSCs and then administering the cells immediately post-thaw may impair their functionality (66). However, the same approach has been used in the majority of clinical trials involving allogeneic MSCs, many of which have generated positive results.

A number of groups have attempted to circumvent the challenges associated with inter-donor variability and extensive MSC expansion using novel manufacturing approaches. One such approach is to generate an MSC bank from pooled bone marrow donations from multiple donors. There is evidence that this approach, known as the "MSC-FFM" method, can facilitate consistency within an MSC bank, with encouraging clinical trial results (40). By pooling donations, a larger quantity of MSCs can be produced compared to a single-donor bank with a similar level of expansion. However, based on the upper end of the dose regimen range used in the initial clinical trial, we calculate that each bank would only suffice for the treatment of approximately 175 patients. There is also a need to investigate consistency between banks produced using this method.

An alternative approach is to rely on pluripotent stem cells (PSCs) as a starting material for the production of MSCs. PSCs have the capacity to replicate indefinitely without loss of pluripotency, in addition to the ability to differentiate into any adult cell type. This means that a single bank of PSCs has the 
potential to give rise to an effectively limitless number of therapeutic cells. There are two types of PSCs: embryonic stem cells (ESCs) and induced pluripotent stem cells (iPSCs). While both types of PSCs have broadly similar properties, research and commercialisation of ESC-based therapies has been hampered by ethical controversy and political/funding constraints. These issues do not apply to iPSCs, which are derived from adult cells. The generation of human iPSCs was first reported by two independent groups in $2007(73,74)$. To illustrate their enormous self-replication capacity, it has been reported that even after $10^{(71)}$-fold expansion in culture, iPSCs retain their ability to differentiate into all three germ-layers (75). We have conducted a Phase 1 clinical trial in SR-aGvHD with iPSCderived MSCs produced using a proprietary process (Cymerus ${ }^{\mathrm{TM}}$, Cynata Therapeutics Limited) (44). In contrast to processes reliant on the isolation of primary MSCs from donated tissue, a single iPSC bank has the capacity to produce 29 million clinical doses (each containing $1 \times 10^{8}$ MSCs) using this process, at current scale. Thus, problems associated with inter-donor variability would be virtually eliminated. Furthermore, as this process achieves its scale by expansion at the iPSC stage, and prior to differentiation of the cells into MSCs, it involves relatively little expansion at the MSC stage. This is expected to minimise the type of functional changes that have been observed after extensive expansion of primary MSCs.

The small number of published studies in chronic GvHD comprise compassionate use studies or Phase 1/2 clinical trials, and all have had small sample sizes $(n=1-14)$. Results have been mixed, with responses of $0-57 \%$ (CR) and $0-80 \%$ (OR), at various, and in some cases unspecified, timepoints $(34,39,47$, $50,51,56,57)$. It is difficult to draw conclusions from this limited dataset.

As represented in Figure 1, multifactorial effects of MSCs have been identified, which include transfer of exosomes, microvesicles and organelles, and paracrine activity mediated by secretion of immunomodulatory molecules (20-26). In recent years, it has been suggested that the immunomodulatory effects of MSCs result in part from apoptosis, and the subsequent release of apoptotic extracellular vesicles and activation of IDO production in macrophages (27). In addition to the fact that MSCs act in numerous different ways, a further complication is that MSCs target a wide range of cells in vivo. In the context of GvHD, the target cells fall into two main categories: (i) immune cells from the host and HSCT donor; and (ii) cells that are damaged by GvHD, such as cells of the skin, liver and gastrointestinal tract. It may be that this diverse arsenal of mechanisms gives MSCs an advantage over more conventional single-target therapeutic agents, especially against a disease such as GvHD, which itself is underpinned by complex pathology involving a multitude of cell types and pathways. However, this

\section{REFERENCES}

1. Garnett C, Apperley JF, Pavlů J. Treatment and Management of GraftVersus-Host Disease: Improving Response and Survival. Ther Adv Hematol (2013) 4(6):366-78. doi: 10.1177/2040620713489842 also makes it extremely challenging to comprehensively elucidate the mechanisms of action of MSCs, either in general or with respect to the treatment of GvHD in particular. An improved understanding of MSC mechanisms of action would be beneficial for the clinical community, as well as providing a basis for the development of in vitro potency assays, to help identify and address problems with MSC variability.

\section{CONCLUSION}

A substantial body of evidence suggests that MSCs have a beneficial effect in treating SR-aGvHD. Recent innovations may be capable of overcoming problems associated with interdonor variability and functional changes associated with extensive culture expansion. Further adequately powered prospective studies are required to confirm efficacy and establish the place of MSC therapy in the treatment of this condition.

Experience to date with MSCs as a treatment for chronic GvHD is much more limited. The prevalence of clinical investigation of MSCs for acute GvHD versus chronic GvHD might suggest that the clinical community has identified more promise in the former, but further investigation in chronic GvHD appears to be warranted.

\section{AUTHOR CONTRIBUTIONS}

KK and JR drafted and reviewed the manuscript. All authors contributed to the article and approved the submitted version.

\section{FUNDING}

Cynata Therapeutics funded the production of the illustration in Figure $\mathbf{1}$ and the manuscript publication fees. This work was supported by a National Health and Medical Research Council Investigator Grant \#1177305 to JR for 'driving clinical cell and gene therapy in Australia'. Additional support was provided by Cure the Future, Therapeutic Innovation Australia and an anonymous foundation to JR.

\section{ACKNOWLEDGMENTS}

The authors thank Ooid Scientific (Fremantle, Western Australia), who prepared Figure 1.

2. Filipovich AH, Weisdorf D, Pavletic S, Socie G, Wingard JR, Lee SJ, et al. National Institutes of Health Consensus Development Project on Criteria for Clinical Trials in Chronic Graft-Versus-Host Disease: I. Diagnosis and Staging Working Group Report. Biol Blood Marrow Transplant (2005) 11:945-56. doi: 10.1016/j.bbmt.2005.09.004 
3. Aractingi S, Chosidow O. Cutaneous Graft-Versus-Host Disease. Arch Dermatol (1998) 134(5):602-12. doi: 10.1001/archderm.134.5.602

4. Inamoto Y, Storer BE, Petersdorf EW, Nelson JL, Lee SJ, Carpenter PA, et al. Incidence, Risk Factors, and Outcomes of Sclerosis in Patients With Chronic Graft-Versus-Host Disease. Blood (2013) 121(25):5098-103. doi: 10.1182/ blood-2012-10-464198

5. Socié G, Ritz J. Current Issues in Chronic Graft-Versus-Host Disease. Blood (2014) 124(3):374-84. doi: 10.1182/blood-2014-01-514752

6. Phelan R, Arora M, Chen M. Current Use and Outcome of Hematopoietic Stem Cell Transplantation: CIBMTR US Summary Slides. (2020). Available at: https://www.cibmtr.org/ReferenceCenter/SlidesReports/SummarySlides/ Pages/index.aspx.

7. Przepiorka D, Weisdorf D, Martin P, Klingemann HG, Beatty P, Hows J, et al. 1994 Consensus Conference on Acute GVHD Grading. Bone Marrow Transplant (1995) 15(6):825-8.

8. Jagasia MH, Greinix HT, Arora M, Williams KM, Wolff D, Cowen EW, et al. National Institutes of Health Consensus Development Project on Criteria for Clinical Trials in Chronic Graft-Versus-Host Disease: I. The 2014 Diagnosis and Staging Working Group Report. Biol Blood Marrow Transplant (2015) 21 (3):389-401. doi: 10.1016/j.bbmt.2014.12.001

9. Penack O, Marchetti M, Ruutu T, Aljurf M, Bacigalupo A, Bonifazi F, et al. Prophylaxis and Management of Graft Versus Host Disease After Stem-Cell Transplantation for Haematological Malignancies: Updated Consensus Recommendations of the European Society for Blood and Marrow Transplantation. Lancet Haematol (2020) 7(2):e157-67. doi: 10.1016/S23523026(19)30256-X

10. Westin JR, Saliba RM, De Lima M, Alousi A, Hosing C, Qazilbash MH, et al. Steroid-Refractory Acute GVHD: Predictors and Outcomes. Adv Hematol (2011) 2011:601953. doi: 10.1155/2011/601953

11. Flowers MED, Martin PJ. How We Treat Chronic Graft-Versus-Host Disease. Blood (2015) 125(4):606-15. doi: 10.1182/blood-2014-08-551994

12. Food and Drug Administration. FDA Approves Ruxolitinib for Acute GraftVersus-Host Disease (2019). Available at: https://www.fda.gov/drugs/ resources-information-approved-drugs/fda-approves-ruxolitinib-acute-graftversus-host-disease (Accessed September 29, 2021).

13. Food and Drug Administration. FDA Approves Belumosudil for Chronic Graft-Versus-Host Disease (2021). Available at: https:/www.fda.gov/drugs/ drug-approvals-and-databases/fda-approves-belumosudil-chronic-graftversus-host-disease (Accessed September 29, 2021).

14. Mannina D, Kröger N. Janus Kinase Inhibition for Graft-Versus-Host Disease: Current Status and Future Prospects. Drugs (2019) 79(14):1499509. doi: 10.1007/s40265-019-01174-1

15. Cottliar JA. Atlas of Graft Versus Host Disease. Cham, Switzzerland: Springer International Publishing AG (2017).

16. Saidu NEB, Bonini C, Dickinson A, Grce M, Inngjerdingen M, Koehl U, et al. New Approaches for the Treatment of Chronic Graft-Versus-Host Disease: Current Status and Future Directions. Front Immunol (2020) 11:578314. doi: 10.3389/fimmu.2020.578314

17. Galderisi U, Peluso G, Di Bernardo G. Clinical Trials Based on Mesenchymal Stromal Cells are Exponentially Increasing: Where are We in Recent Years? Stem Cell Rev Rep (2021) 16:1-14. doi: 10.1007/s12015-021-10231-w

18. Crippa S, Santi L, Berti M, De Ponti G, Bernardo ME. Role of Ex Vivo Expanded Mesenchymal Stromal Cells in Determining Hematopoietic Stem Cell Transplantation Outcome. Front Cell Dev Biol (2021) 9:663316. doi: $10.3389 /$ fcell.2021.663316

19. Introna M, Golay J. Tolerance to Bone Marrow Transplantation: Do Mesenchymal Stromal Cells Still Have a Future for Acute or Chronic GvHD? Front Immunol (2020) 11:609063. doi: 10.3389/fimmu.2020.609063

20. Spees JL, Lee RH, Gregory CA. Mechanisms of Mesenchymal Stem/Stromal Cell Function. Stem Cell Res Ther (2016) 7:125. doi: 10.1186/s13287-0160363-7

21. Sharma RR, Pollock K, Hubel A, McKenna D. Mesenchymal Stem or Stromal Cells: A Review of Clinical Applications and Manufacturing Practices. Transfusion (2014) 54(5):1418-37. doi: 10.1111/trf.12421

22. Galipeau J, Sensébé L. Mesenchymal Stromal Cells: Clinical Challenges and Therapeutic Opportunities. Cell Stem Cell (2018) 22(6):824-33. doi: 10.1016/ j.stem.2018.05.004
23. Harrell CR, Jovicic N, Djonov V, Arsenijevic N, Volarevic V. Mesenchymal Stem Cell-Derived Exosomes and Other Extracellular Vesicles as New Remedies in the Therapy of Inflammatory Diseases. Cells (2019) 8(12): E1605. doi: 10.3390/cells8121605

24. Weiss ARR, Dahlke MH. Front. Immunomodulation by Mesenchymal Stem Cells (MSCs): Mechanisms of Action of Living, Apoptotic, and Dead MSCs. Front Immunol (2019) 10:1191. doi: 10.3389/fimmu.2019.01191

25. Martin I, Galipeau J, Kessler C, Le Blanc K, Dazzi F. Challenges for Mesenchymal Stromal Cell Therapies. Sci Transl Med (2019) 20 11(480):pii: eaat2189. doi: 10.1126/scitranslmed.aat2189

26. Terness P, Bauer TM, Röse L, Dufter C, Watzlik A, Simon H, et al. Inhibition of Allogeneic T Cell Proliferation by Indoleamine 2,3-Dioxygenaseexpressing Dendritic Cells. J Exp Med (2002) 196(4):447-57. doi: 10.1084/ jem.20020052

27. Fu Y, Sui B, Xiang L, Yan X, Wu D, Shi S, et al. Emerging Understanding of Apoptosis in Mediating Mesenchymal Stem Cell Therapy. Cell Death Dis (2021) 12:596. doi: 10.1038/s41419-021-03883-6

28. Galleu A, Riffo-Vasquez Y, Trento C, Lomas C, Dolcetti L, Cheung TS, et al. Apoptosis in Mesenchymal Stromal Cells Induces In Vivo Recipient-Mediated Immunomodulation. Sci Transl Med (2017) 9(416):7828. doi: 10.1126/ scitranslmed.aam7828

29. Ozay EI, Vijayaraghavan J, Gonzalez-Perez G, Shanthalingam S, Sherman HL, Garrigan DT, et al. Cymerus ${ }^{\mathrm{TM}}$ iPSC-MSCs Significantly Prolong Survival in a Pre-Clinical, Humanized Mouse Model of Graft-Vs-Host Disease. Stem Cell Res (2019) 35:101401. doi: 10.1016/j.scr.2019.101401

30. Le Blanc K, Rasmusson I, Sundberg B, Götherström C, Hassan M, Uzunel M, et al. Treatment of Severe Acute Graft-Versus-Host Disease With Third Party Haploidentical Mesenchymal Stem Cells. Lancet (2004) 363:1439-41. doi: 10.1016/S0140-6736(04)16104-7

31. Kebriaei P, Isola L, Bahceci E, Holland K, Rowley S, McGuirk J, et al. Adult Human Mesenchymal Stem Cells Added to Corticosteroid Therapy for the Treatment of Acute Graft-Versus-Host Disease. Biol Blood Marrow Transplant (2009) 15:804 11. doi: 10.1016/j.bbmt.2008.03.012

32. Soder RP, Dawn B, Weiss ML, Dunavin N, Weir S, Mitchell J, et al. A Phase I Study to Evaluate Two Doses of Wharton's Jelly-Derived Mesenchymal Stromal Cells for the Treatment of De Novo High-Risk or SteroidRefractory Acute Graft Versus Host Disease. Stem Cell Rev Rep (2020) 16:979-91. doi: 10.1007/s12015-020-10015-8

33. von Bonin M, Stölzel F, Goedecke A, Richter K, Wuschek N, Hölig K, et al. Treatment of Refractory Acute GVHD With Third-Party MSC Expanded in Platelet Lysate-Containing Medium. Bone Marrow Transplant (2009) 43:24551. doi: 10.1038/bmt.2008.316

34. Lucchini G, Introna M, Dander E, Rovelli A, Balduzzi A, Bonanomi S, et al. Platelet-Lysate-Expanded Mesenchymal Stromal Cells as a Salvage Therapy for Severe Resistant Graft-Versus-Host Disease in a Pediatric Population. Biol Blood Marrow Transplant (2010) 16:1293-301. doi: 10.1016/j.bbmt. 2010.03.017

35. Muroi K, Miyamura K, Ohashi K, Murata M, Eto T, Kobayashi N, et al. Unrelated Allogeneic Bone Marrow-Derived Mesenchymal Stem Cells for Steroid-Refractory Acute Graft-Versus-Host Disease: A Phase I/II Study. Int J Hematol (2013) 98:206-13. doi: 10.1007/s12185-013-1399-4

36. Introna M, Lucchini G, Dander E, Galimberti S, Rovelli A, Balduzzi A. Treatment of Graft Versus Host Disease With Mesenchymal Stromal Cells: A Phase I Study on 40 Adult and Pediatric Patients. Biol Blood Marrow Transplant (2014) 20:375-81. doi: 10.1016/j.bbmt. 2013.11.033

37. Zhao K, Lou R, Huang F, Peng Y, Jiang Z, Huang K, et al. Immunomodulation Effects of Mesenchymal Stromal Cells on Acute Graft-Versus-Host Disease After Hematopoietic Stem Cell Transplantation. Biol Blood Marrow Transplant (2015) 21:97-104. doi: 10.1016/j.bbmt.2014.09.030

38. Muroi K, Miyamura K, Okada M, Yamashita T, Murata M, Ishikawa T, et al Bone Marrow-Derived Mesenchymal Stem Cells (JR-031) for Steroid -Refractory Grade III or IV Acute Graft-Versus-Host Disease: A Phase II/III Study. Int J Hematol (2016) 103:243-50. doi: 10.1007/s12185-0151915-9

39. Salmenniemi U, Itälä-Remes $M$, Nystedt J, Putkonen $M$, Niittyvuopio R, Vettenranta K, et al. Good Responses But High TRM in Adult Patients After 
MSC Therapy for GvHD. Bone Marrow Transplant (2017) 52:606-8. doi: 10.1038/bmt.2016.317

40. Bader P, Kuçi Z, Bakhtiar S, Basu O, Bug G, Dennis M, et al. Effective Treatment of Steroid and Therapy-Refractory Acute Graft Versus-Host Disease With a Novel Mesenchymal Stromal Cell Product (MSC-FFM). Bone Marrow Transplant (2018) 53:852-62. doi: 10.1038/s41409-018-0102-z

41. Kebriaei P, Hayes J, Daly A, Uberti J, Marks DI, Soiffer R, et al. A Phase 3 Randomized Study of Remestemcel-L Versus Placebo Added to Second-Line Therapy in Patients With Steroid-Refractory Acute Graft-Versus-Host Disease. Biol Blood Marrow Transplant (2020) 26(5):835-44. doi: 10.1016/ j.bbmt.2019.08.029

42. Kurtzberg J, Prockop D, Chaudhury S, Horn B, Nemecek E, Prasad V, et al. Study 275: Updated Expanded Access Program for Remestemcel-L in SteroidRefractory Acute Graft-Versus-Host Disease in Children. Biol Blood Marrow Transplant (2020) 26:855-64. doi: 10.1016/j.bbmt.2020.01.026

43. Kurtzberg J, Abdel-Azim H, Carpenter P, Chaudhury S, Horn B, Mahadeo K, et al. A Phase 3, Single-Arm, Prospective Study of Remestemcel-L, Ex Vivo Culture-Expanded Adult Human Mesenchymal Stromal Cells for the Treatment of Pediatric Patients Who Failed to Respond to Steroid Treatment for Acute Graft-Versus-Host Disease. Biol Blood Marrow Transplant (2020) 26:845-54. doi: 10.1016/j.bbmt.2020.01.018

44. Bloor AJC, Patel A, Griffin JE, Gilleece MH, Radia R, Yeung DT, et al. Production, Safety and Efficacy of iPSC-Derived Mesenchymal Stromal Cells in Acute Steroid-Resistant Graft Versus Host Disease: A Phase I, Multicenter, Open-Label, Dose-Escalation Study. Nat Med (2020) 26:1720-5. doi: 10.1038/ s41591-020-1050-x

45. Prasad VK, Lucas KG, Kleiner GI, Talano JAM, Jacobsohn D, Broadwater G, et al. Efficacy and Safety of Ex Vivo Cultured Adult Human Mesenchymal Stem Cells (Prochymal ${ }^{\mathrm{TM}}$ ) in Pediatric Patients With Severe Refractory Acute Graft-Versus-Host Disease in a Compassionate Use Study. Biol Blood Marrow Transplant (2011) 17(4):534-41. doi: 10.1016/j.bbmt.2010.04.014

46. Sánchez-Guijo F, Caballero-Velázquez T, López-Villar O, Redondo A, Parody R, Martínez C, et al. Sequential Third-Party Mesenchymal Stromal Cell Therapy for Refractory Acute Graft-Versus-Host Disease. Biol Blood Marrow Transplant (2014) 20:1580-5. doi: 10.1016/j.bbmt. 2014.06.015

47. Ringden O, Uzunel M, Rasmusson I, Remberger M, Sundberg B, Lönnies H, et al. Mesenchymal Stem Cells for Treatment of Therapy-Resistant GraftVersus-Host Disease. Transplantation (2006) 81:1390-7. doi: 10.1097/ 01.tp.0000214462.63943.14

48. Le Blanc K, Frassoni F, Ball L, Locatelli F, Roelofs H, Lewis I, et al. Mesenchymal Stem Cells for Treatment of Steroid-Resistant, Severe, Acute Graft-Versus-Host Disease: A Phase II Study. Lancet (2008) 371:1579-86. doi: 10.1016/S0140-6736(08)60690-X

49. Arima N, Nakamura F, Fukunaga A, Hirata H, Machida H, Kouno S, et al. Single Intra-Arterial Injection of Mesenchymal Stromal Cells for Treatment of Steroid-Refractory Acute Graft-Versus-Host Disease: A Pilot Study. Cytotherapy (2010) 12:265-8. doi: 10.3109/14653240903390795

50. Pérez-Simon JA, López-Villar O, Andreu EJ, Rifón J, Muntion S, Diez Campelo M, et al. Mesenchymal Stem Cells Expanded In Vitro With Human Serum for the Treatment of Acute and Chronic Graft-Versus-Host Disease: Results of a Phase I/II Clinical Trial. Haematologica (2011) 96:10726. doi: 10.3324/haematol.2010.038356

51. Herrmann R, Sturm M, Shaw K, Purtill D, Cooney J, Wright M, et al. Mesenchymal Stromal Cell Therapy for Steroid-Refractory Acute and Chronic Graft Versus Host Disease: A Phase 1 Study. Int J Hematol (2012) 95:182-8. doi: 10.1007/s12185-011-0989-2

52. Ball LM, Bernardo ME, Roelofs H, van Tol MJD, Contoli B, Zwaginga JJ, et al. Multiple Infusions of Mesenchymal Stromal Cells Induce Sustained Remission in Children With Steroid-Refractory, Grade III-IV Acute Graft-Versus-Host Disease. Br J Haematol (2013) 163:501-9. doi: 10.1111/ bjh. 12545

53. Resnick IB, Barkats C, Shapira MY, Stepensky P, Bloom AI, Shimoni A, et al. Treatment of Severe Steroid Resistant Acute GVHD With Mesenchymal Stromal Cells (MSC). Am J Blood Res (2013) 3:225-38.

54. Von Dalowski F, Kramer M, Wermke M, Wehner R, Röllig C, Alakel N, et al. Mesenchymal Stromal Cells for Treatment of Acute Steroid-Refractory Graft
Versus Host Disease: Clinical Responses and Long-Term Outcome. Stem Cells (2016) 34:357-66. doi: 10.1002/stem.2224

55. Dotoli GM, De Santis GC, Orellana MD, de Lima Prata K, Caruso SR, Fernandes TR, et al. Mesenchymal Stromal Cell Infusion to Treat SteroidRefractory Acute GvHD III/IV After Hematopoietic Stem Cell Transplantation. Bone Marrow Transplant (2017) 52:859-62. doi: 10.1038/ bmt.2017.35

56. Jurado M, de la Mata C, Ruiz García A, López-Fernández E, Espinosa O, Remigia MJ, et al. Adipose Tissue-Derived Mesenchymal Stromal Cells as Part of Therapy for Chronic Graft-Versus-Host Disease: A Phase I/II Study. Cytotherapy (2017) 19:927-36. doi: 10.1016/j.jcyt.2017.05.002

57. Boberg E, von Bahr L, Afram G, Lindström C, Ljungman P, Heldring N, et al. Treatment of Chronic GvHD With Mesenchymal Stromal Cells Induces Durable Responses: A Phase II Study. Stem Cells Transl Med (2020) 9:1190202. doi: $10.1002 / \mathrm{sctm} .20-0099$

58. Thompson M, Mei SHJ, Wolfe D, Champagne J, Fergusson D, Stewart DJ, et al. Cell Therapy With Intravascular Administration of Mesenchymal Stromal Cells Continues to Appear Safe: An Updated Systematic Review and Meta-Analysis. EClinicalMedicine (2020) 19:100249. doi: 10.1016/ j.eclinm.2019.100249

59. Zeiser R, von Bubnoff N, Butler J, Mohty M, Niederwieser D, Or R, et al. Ruxolitinib for Glucocorticoid-Refractory Acute Graft-Versus-Host Disease. N Engl J Med (2020) 382(19):1800-10. doi: 10.1056/NEJMoa1917635

60. Jagasia M, Perales MA, Schroeder MA, Ali H, Shah NN, Chen YB, et al. Ruxolitinib for the Treatment of Steroid-Refractory Acute GVHD (REACH1): A Multicenter, Open-Label, Phase 2 Trial. Blood (2020) 135(20):1739-49. doi: 10.1182/blood.2020004823

61. De Jong CN, Saes L, Klerk CPW, van der Klift M, Cornelissen JJ, Broers AEC. Etanercept for Steroid-Refractory Acute Graft-Versus-Host Disease: A Single Center Experience. PloS One (2017) 12(10):e0187184. doi: 10.1371/ journal.pone. 0187184

62. Park JH, Lee HJ, Kim SR, Song GW, Lee SK, Park SY, et al. Etanercept for Steroid-Refractory Acute Graft Versus Host Disease Following Allogeneic Hematopoietic Stem Cell Transplantation. Korean J Intern Med (2014) 29 (5):6306. doi: 10.3904/kjim.2014.29.5.630

63. Greinix HT, Volc-Platzer B, Kahls P, Fischer G, Rosenmayr A, Keil F, et al. Extracorporeal Photochemotherapy in the Treatment of Severe SteroidRefractory Acute Graft-Versus-Host Disease: A Pilot Study. Blood (2000) 96:2426-31. doi: 10.1182/blood.V96.7.2426

64. US National Library of Medicine. A Study to Compare T-Guard vs Ruxolitinib for Treatment of Steroid-Refractory Acute Graft-Versus-Host Disease (SRaGVHD) (BMT CTN 2002) (2002)(2021). Available at: https://clinicaltrials. gov/ct2/show/NCT04934670 (Accessed September 29, 2021).

65. Martin PJ, Rizzo JD, Wingard JR, Ballen K, Curtin PT, Cutler C, et al. Firstand Second-Line Systemic Treatment of Acute Graft-Versus-Host Disease: Recommendations of the American Society of Blood and Marrow Transplantation. Biol Blood Marrow Transplant (2012) 18:1150-63. doi: 10.1016/j.bbmt.2012.04.005

66. Galipeau J. The Mesenchymal Stromal Cells Dilemma-Does a Negative Phase III Trial of Random Donor Mesenchymal Stromal Cells in Steroid-Resistant Graft-Versus-Host Disease Represent a Death Knell or a Bump in the Road? Cytotherapy (2013) 15(1):2-8. doi: 10.1016/j.jcyt.2012.10.002

67. Wagner W, Horn P, Castoldi M, Diehlmann A, Bork S, Saffrich R, et al. Replicative Senescence of Mesenchymal Stem Cells: A Continuous and Organized Process. PloS One (2008) 3(5):e2213. doi: 10.1371/journal. pone.0002213

68. De Witte SFH, Lambert EE, Merino A, Strini T, Douben HJCW, O’Flynn L, et al. Aging of Bone Marrow- and Umbilical Cord-Derived Mesenchymal Stromal Cells During Expansion. Cytotherapy (2017) 19:798-807. doi: 10.1016/j.jcyt.2017.03.071

69. von Bahr L, Sundberg B, Lönnies L, Sander B, Karbach H, Hägglund H, et al. Long-Term Complications, Immunologic Effects, and Role of Passage for Outcome in Mesenchymal Stromal Cell Therapy. Biol Blood Marrow Transplant (2012) 18(4):557-64. doi: 10.1016/j.bbmt.2011.07.023

70. Siegel G, Kluba T, Hermanutz-Klein U, Bieback K, Northoff H, Schäfer R. Phenotype, Donor Age and Gender Affect Function of Human Bone MarrowDerived Mesenchymal Stromal Cells. BMC Med (2013) 11:146. doi: 10.1186/ 1741-7015-11-146 
71. Wegmeyer H, Bröske AM, Leddin M, Kuentzer K, Nisslbeck AK, Hupfeld J, et al. Mesenchymal Stromal Cell Characteristics Vary Depending on Their Origin. Stem Cells Dev (2013) 22(19):2606-18. doi: 10.1089/ scd.2013.0016

72. Ketterl N, Brachtl G, Schuh C, Bieback K, Schallmoser K, Reinisch A, et al. A Robust Potency Assay Highlights Significant Donor Variation of Human Mesenchymal Stem/Progenitor Cell Immune Modulatory Capacity and Extended Radio-Resistance. Stem Cell Res Ther (2015) 6:236. doi: 10.1186/ s13287-015-0233-8

73. Takahashi K, Tanabe K, Ohnuki M, Narita M, Ichisaka T, Tomoda K, et al. Induction of Pluripotent Stem Cells From Adult Human Fibroblasts by Defined Factors. Cell (2007) 131:861-72. doi: 10.1016/j.cell. 2007.11.019

74. Yu J, Vodyanik MA, Smuga-Otto K, Antosiewicz-Bourget J, Frane JL, Tian S, et al. Induced Pluripotent Stem Cell Lines Derived From Human Somatic Cells. Science (2007) 318:1917-20. doi: 10.1126/ science. 1151526

75. Lei Y, Schaffer DV. A Fully Defined and Scalable 3D Culture System for Human Pluripotent Stem Cell Expansion and Differentiation. Proc Natl Acad Sci USA (2013) 24:110:E5039-5048. doi: 10.1073/pnas. 1309408110
Conflict of Interest: KK is an employee and shareholder of Cynata Therapeutics. JR has acted as a consultant for and received travel grants from Cynata Therapeutics.

The authors declare that this study received funding from Cynata Therapeutics. The funder was not involved in the study design, collection, analysis, interpretation of data, the writing of this article or the decision to submit it for publication, outside of the contributions of author KK.

Publisher's Note: All claims expressed in this article are solely those of the authors and do not necessarily represent those of their affiliated organizations, or those of the publisher, the editors and the reviewers. Any product that may be evaluated in this article, or claim that may be made by its manufacturer, is not guaranteed or endorsed by the publisher.

Copyright $\odot 2021$ Kelly and Rasko. This is an open-access article distributed under the terms of the Creative Commons Attribution License (CC BY). The use, distribution or reproduction in other forums is permitted, provided the original author(s) and the copyright owner(s) are credited and that the original publication in this journal is cited, in accordance with accepted academic practice. No use, distribution or reproduction is permitted which does not comply with these terms. 